\title{
Effect of Pre-Blending and Phase-Mixing Methods on Properties of Natural Rubber and Acrylonitrile Butadiene Rubber Blends Filled with Nano Silica Extracted from Rice Husk Ash
}

\author{
H.G.I.M. Wijesinghe1,*, G.R.V.S. Gamlath ${ }^{1}$, A.M.W.K. Senevirathna ${ }^{1}$, D.G. Edirisinghe ${ }^{2}$, \\ R.R.W.M.U.G.K. Wadugodapitiya ${ }^{1}$, T.A.R.W.M.M.C.G. Bandara1 ${ }^{1}$ B.N.S. Bandara ${ }^{1}$
}

${ }_{1}^{1}$ Department of Export Agriculture, Faculty of Animal Science and Export Agriculture, Uva Wellassa University, Passara Road, Badulla, 90 000, Sri Lanka. ${ }^{2}$ Department of Rubber Technology and Development, Rubber Research Institute of Sri Lanka, Thelawala Road, Rathmalana, 10390, Sri Lanka.

\section{A R T I C L E D E T A I L S}

\section{Article history:}

Received 15 December 2020

Accepted 03 January 2021

Available online 17 January 2021

\section{Keywords:}

Natural Rubber

Acrylonitrile Butadiene Rubber

Rice Husk

Nano Silica

\begin{abstract}
A B S T R A C T
Properties of natural rubber (NR) and acrylonitrile butadiene rubber (NBR) blends are varied due to blending method. The literature is evident that the pre-blending and phase-mixing methods affect the properties of blends while opposite arguments are also available. Hence, that fact was interested to study using NR/NBR blends filled with rice husk ash nano silica (RHANS) having an average particle size of 50 $\mathrm{nm}-100 \mathrm{~nm}$ with some micro-scale agglomerates. The structure of RHANS was proved using X-ray diffraction and Fourier transform infrared spectrophotometric analyses. Blends were prepared following both blending methods by varying NR to NBR ratio as 0:100, 20:80, 40:60, 60:40, 80:20, and 100:0 while filling 25 parts per hundred parts of rubber of RHANS. The control was the ASTM formulation for oil seals. Vulcanization properties of blends showed acceptable levels with extended scorch and cure times and high torque properties. Blends indicated less tensile and tear strength compared to the control while showing acceptable hardness, compression set, and swell ing properties. Overall, there is a possibility to use RHANS in NR/NBR blends and it was found that the blending method does not affect the properties of the NR/NBR blends.
\end{abstract}

\section{Introduction}

Rubber blends are the mixtures of two or more rubber materials mixed to combine the individual properties into one material. Normally, rubber blends are used to make products with synergistic properties [1]. The dispersion of each rubber component in the blends determines the final properties of the products made of such a mixture [2]. When rubber is blended with another rubber, the resulting mixture has a weight-average effect on the properties of the individual rubber material. Therefore, the ratio of each rubber material in the blends and the method of mixing which determines the dispersion of each rubber component in the blends can affect the properties of the blends. Generally, rubbers are blended using several methods in the industry such as latex blending, solution blending, and mechanical blending [3]. However, all these methods of blending can be divided into two main categories as pre-blending and phase-mixing.

In pre-blending methods, the general rubber compounding ingredients are added to a mixture of rubbers in a way similar to that of a single elastomer. During the phase-mixing method, separate master batches of rubber compounds which are containing all the compounding ingredients are mixed into one rubber compound [4]. Also, Aerankavil [4] has mentioned that mixing compounding ingredients directly into a blend of the rubbers (pre-blending) has advantages such as cost and time effectiveness over the phase-mixing method of rubber blending. At the same time, Bristow [5] has also found that there was no difference in the properties of blends prepared according to these two methods of blending. Further, Lewan [6] has found that the properties of rubber blends are related to rubber ratio, phase morphology, interfacial tension, crosslink distribution, filler incorporated, and filler distribution between phases of rubbers in the blends. However, Edirisinghe [7] has reported that the method of preparing rubber blends (pre-blending and phase-mixing) affects the properties mentioned above.

Natural rubber (NR) and Acrylonitrile butadiene rubber (NBR) blends were selected in this study to evaluate the properties against two main blending methods since these rubbers are used in rubber articles where good mechanical properties and oil resistance are required. According to the literature, improved mechanical properties and oil resistance in NR/NBR blends which have been compatibilized using grafted NR have been investigated [8]. Further, Yuniari et al. [1] have incorporated epoxide natural rubber into NR/NBR blends and have observed better adhesion and increased crosslink density. Thus, NR/NBR blends have been investigated for the properties because it couples the superior mechanical properties of NR with special oil and chemical resistance properties of NBR into single rubber material $[1,9,10]$.

When considering the filler materials which are used in such blends, carbon black can be identified as the extensively used filler in the rubber industry [11]. Although carbon black (CB) is highly used, it cannot be us ed for applications where color is significant. As a solution to this, commercial-grade silica (white-colored reinforcing filler) is used while improving dynamic properties and heat-buildup of rubber products [10]. However, the use of such silica is not economical because it is extracted mostly from the earth's crust using high technologies with the consumption of a high amount of energy [12]. Therefore, Todkar et al. [12] have reported that extraction of silica from rice husk is cost-effective since it is widely available around the world as an agro-waste and it consumes much lower energy and money compared to the current technologies used to produce silica from quartz, etc. This rice husk has a high ash content ranging from $18 \%$ to $20 \%$ and the silica content in the ash is ranged from $90 \%$ to $98 \%$ [13]. As per the global rice production, rice husk can be considered as a reliable source of silica which can be extracted and used in rubber products. Nonetheless, the propensity to agglomerate the silica when it is mixed with rubber is a major drawback of using such silica. This occurs due to the presence of silanol groups on the silica surface [10].

To overcome this issue, coupling agents such as bifunctional organosilanes, for example, bis(triethoxysilylpropyl)tetrasulphide (TESPT) are used in rubber compounds [14]. Therefore, there is a possibility to introduce rice husk ash silica into NR/NBR blends while using TESPT like organosilanes as compatibilizers of rubber and filler. Also, rice husk silica could have some effect on making compatible both rubber phases at their interfaces of the blends due to its surface polarity. As well as the effect of the method of blending on the properties of NR/NBR filled with rice husk ash nano silica has not been studied according to the literature. Therefore, based on these facts, it was 
interested to study the effect of blending methods (pre-blending and phase-mixing) on properties of NR and NBR blends that were filled with rice husk ash nano silica considering this effort as a value addition to rice husk waste.

\section{Experimental Methods}

\subsection{Materials}

Natural rubber in the form of Ribbed Smoked Sheet (RSS No. 1) and acrylonitrile butadiene rubber were purchased from Industrial Development Board, Peliyagoda, Sri Lanka. Other chemical ingredients were purchased from the Glochem Enterprise, Colombo 11, Sri Lanka. Rice husk ash was obtained from a brick factory located in Badulla, Sri Lanka.

\subsection{Extraction of Nano Silica from Rice Husk Ash}

Rice husk ash (RHA) that was collected from a brick factory was washed using distilled water and kept in an air circulating oven at $105{ }^{\circ} \mathrm{C}$ until a constant mass is obtained. The dried RHA sample was completely burnt in a muffle furnace (Hobersal, Spain) at $700{ }^{\circ} \mathrm{C}$ for 6 hours. The burnt RHA samples were cooled overnight and digested by boiling for three hours in a round bottom flask using 3 moldm $^{-3} \mathrm{NaOH}$ solution while maintaining the RHA: $\mathrm{NaOH}$ ratio at 1:8 followed by cooling the mixture to room temperature. After that 2.5 moldm$^{-3}$ sulphuric acid was added to the mixture until the $\mathrm{pH}$ of the solution become 2 followed by the addition of ammonia until $\mathrm{pH}$ reached 8.5 at room temperature to precipitate silica. Then, the solution was filtered and the precipitated silica sample was dried at $120^{\circ} \mathrm{C}$ for 12 hours using an air circulating oven. The dried silica sample was refluxed with 6 moldm$^{-3}$ hydrochloric acid for 4 hours and it was washed repeatedly with deionized water until the solution becomes acidfree. Then it was filtered and dried at $105{ }^{\circ} \mathrm{C}$ for 2 hours until a constant weight is obtained. Finally, the silica sample was powdered using a ball mill.

\subsection{Characterization of Rice Husk Ash Nano Silica (RHANS)}

The X-ray diffraction and Fourier transform infrared spectroscopy (FTIR) analysis were conducted using the X-ray diffractometer (RIGAKU, Japan) and the FTIR spectrophotometer (Bruker, German) respectively. The averaged particle sizes of RHANS were calculated using the Scherrer equation based on the data obtained from X-ray diffraction analysis.

\subsection{Preparation of NR/NBR Blend Compounds}

The formulation of NR/NBR blend compounds filled with RHANS was developed referring to the American standard testing method (ASTM) reference formulation for oil seals [7] and it is presented in Table 1. The blends were prepared according to pre-blending and phase-mixing methods. The carbon black filler used in the control was replaced using RHANS once NR/NBR blend compound series was prepared.

\subsection{Preparation of Pre-Blended NR/NBR Blend Compounds}

NR and NBR were blended using a two-roll mill (CT, Thailand) as the ratios given in Table 1 , followed by mixing other compounding ingredients with the prepared NR/NBR blends. Then the blend compounds were matured for 24 hours and sulphur and accelerators (TMTD and TBBS) were mixed with the blend compounds. This was followed separately to overcome the scorching problems of compounds due to the curing system (sulphur and accelerators). The temperature of the two-roll mill was maintained between $70{ }^{\circ} \mathrm{C}$ and $100{ }^{\circ} \mathrm{C}$ when blending of rubber and mixing of ingredients were carried out.

\subsection{Preparation of Phase-Mixed NR/NBR Blend Compounds}

Two separate masterbatches of NR and NBR were prepared using the same two roll mill (CT, Thailand). A half amount of compounding ingredients given in Table 1 was mixed with each master batch of NR and NBR maintaining the same mixing condition as mentioned above. Then the required amounts of rubber compounds were taken from each NR and NBR master batch and mixed to make phase-mixed NR/NBR blend compounds. After that these compounds were matured for 24 hours and curing systems were incorporated.

\subsection{Determination of Vulcanization Properties}

The cure time ( $\left.\mathrm{Tc}_{90}\right)$, scorch time ( $\left.\mathrm{Ts}_{2}\right)$, and maximum torque $(\mathrm{MH})$, minimum torque (ML) of NR/NBR blends were measured using Moving Die Rheometer (Alpha Technologies, USA) at $150{ }^{\circ} \mathrm{C}$ following ISO 3417:2008 procedure.

https://doi.org/10.30799/jnst.319.21070101 


\subsection{Fourier Transformation Infrared Spectroscopy (FTIR)}

The FTIR spectroscopy of silica extracted from RHA is shown in Fig. 2. The broad peak of wavenumber ranged from $3800 \mathrm{~cm}^{-1}$ to $3000 \mathrm{~cm}^{-1}$ represents the stretching and vibration modes of silanol hydroxyl groups $(\mathrm{O}-\mathrm{H})$ and hydroxyl groups of adsorbed water molecules on to the silica surface. The peak at $1632 \mathrm{~cm}^{-1}$ wavenumber shows the bending vibration mode of hydroxyl groups of adsorbed water. The asymmetric and symmetric vibration modes of $\mathrm{Si}-\mathrm{O}$-Si bonds are represented by the peaks of $1095 \mathrm{~cm}^{-1}$ and $800 \mathrm{~cm}^{-1}$ wavenumbers respectively [16,17]. Also, Fig. 3 shows the FTIR spectrum of commercial silica and RHANS. According to the results of Fig. 3, it can be reported that the RHANS is successfully extracted from RHA and it is chemically compatible with commercial silica.

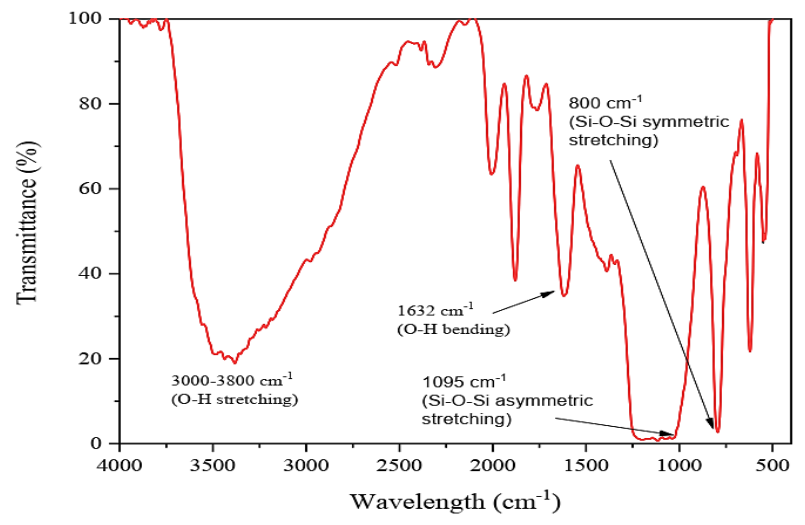

Fig. 2 FTIR spectrum of RHANS

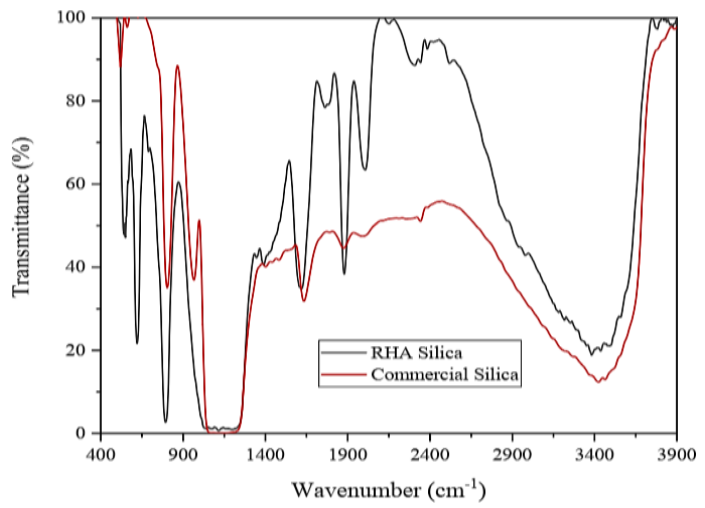

Fig. 3 FTIR spectrum of commercial silica and RHA silica

Table 2 Vulcanization properties of pre-blended and phase-mixed NR/NBR blends

\begin{tabular}{|c|c|c|c|c|c|c|}
\hline \multirow{2}{*}{$\begin{array}{l}\text { Blending } \\
\text { method }\end{array}$} & \multirow{2}{*}{$\begin{array}{l}\text { NR/NBR } \\
\text { blend }\end{array}$} & \multicolumn{5}{|c|}{ Vulcanization properties } \\
\hline & & $\begin{array}{l}\mathrm{ML} \\
(\mathrm{dNm})\end{array}$ & $\begin{array}{l}\text { MH } \\
(\mathrm{dNm})\end{array}$ & $\begin{array}{l}\mathrm{Ts}_{2} \\
(\mathrm{~s})\end{array}$ & $\mathrm{Tc}_{90}(\mathrm{~s})$ & $\begin{array}{l}\text { Cure rate } \\
\text { index }\left(\mathrm{s}^{-1}\right)\end{array}$ \\
\hline Control & $\begin{array}{l}\text { Only NBR } \\
(100)\end{array}$ & 1.8 & 25.1 & 114 & 396 & 0.4 \\
\hline \multirow[t]{6}{*}{$\begin{array}{l}\text { Pre-blended } \\
\text { compounds }\end{array}$} & $\begin{array}{l}\text { NR:NBR } \\
0: 100\end{array}$ & 0.3 & 17.3 & 186 & 858 & 0.1 \\
\hline & $\begin{array}{l}\text { NR:NBR } \\
20: 80\end{array}$ & 0.2 & 16.3 & 186 & 1014 & 0.1 \\
\hline & $\begin{array}{l}\text { NR:NBR } \\
40: 60\end{array}$ & 0.2 & 15.4 & 180 & 804 & 0.2 \\
\hline & $\begin{array}{l}\text { NR:NBR } \\
60: 40\end{array}$ & 0.1 & 12.0 & 204 & 858 & 0.2 \\
\hline & $\begin{array}{l}\text { NR:NBR } \\
80: 20\end{array}$ & 0.1 & 12.9 & 126 & 714 & 0.2 \\
\hline & $\begin{array}{l}\text { NR:NBR } \\
\text { 100:0 }\end{array}$ & 0.2 & 12.7 & 91 & 501 & 0.2 \\
\hline \multirow[t]{6}{*}{$\begin{array}{l}\text { Phase-mixed } \\
\text { compounds }\end{array}$} & $\begin{array}{l}\text { NR:NBR } \\
0: 100\end{array}$ & 0.3 & 17.3 & 186 & 858 & 0.1 \\
\hline & $\begin{array}{l}\text { NR:NBR } \\
20: 80\end{array}$ & 0.2 & 18.1 & 150 & 762 & 0.2 \\
\hline & $\begin{array}{l}\text { NR:NBR } \\
40: 60\end{array}$ & 0.2 & 12.3 & 216 & 834 & 0.2 \\
\hline & $\begin{array}{l}\text { NR:NBR } \\
60: 40\end{array}$ & 0.1 & 13.9 & 156 & 744 & 0.2 \\
\hline & $\begin{array}{l}\text { NR:NBR } \\
80: 20\end{array}$ & 0.1 & 12.7 & 144 & 738 & 0.2 \\
\hline & $\begin{array}{l}\text { NR:NBR } \\
100: 0\end{array}$ & 0.2 & 12.6 & 90 & 504 & 0.2 \\
\hline
\end{tabular}

The vulcanization properties of pre-blended and phase-mixed NR/NBR blends are shown in Table 2. The control has shown higher ML and MH values due to the presence of $60 \mathrm{phr}$ of carbon black in the control sample. The lesser reinforcement of RHANS in the blends can be a reason for lower ML and MH values. The MH and ML values of pre-blended and phasemixed blends have reduced when the NR ratio of the blends is increased. This may be due to the poor compatibility between hydrophilic RHANS and hydrophobic NR. Since the NBR and RHANS have some polarity and thus compatibility, the NBR rich blends have shown high MH and ML values. However, both methods have not shown a significant difference between $\mathrm{MH}$ and $\mathrm{ML}$ values. The scorch time $\left(\mathrm{Ts}_{2}\right)$ and cure time $\left(\mathrm{Tc}_{90}\right)$ of control are $114 \mathrm{~s}$ and $396 \mathrm{~s}$ respectively. Compared to the control the blends have shown lower values for these two properties. This could be attributed to the presence of pre-vulcanizing inhibitor $(\mathrm{N}$ cyclohexylthiophthalamide) in the blend compounds which is not available in the control. Also, the studies conducted by Chuayjuljit et al. [18] mentioned that the reinforcement by rice husk silica may be another reason for having higher curing times. Further, it can be observed that the $\mathrm{Ts}_{2}$ and $\mathrm{Tc}_{90}$ are reduced with the increase of NR content in the blends. The presence of more unsaturated double bonds could facilitate higher vulcanization efficiencies and thus the blends with a high NR ratio could show lower $\mathrm{Ts}_{2}$ and $\mathrm{Tc}_{90}$ values compared to that of high NBR containing blends [19]. Both pre-blended and phase-mixed blends have not shown a significant difference between $\mathrm{Ts}_{2}$ and $\mathrm{T} \mathrm{c}_{90}$ values. The cure rate index of blends is lesser compared to the control. Therefore, it can be reported that the method of preparing NR/NBR blends has not affected the vulcanization properties.

\subsection{Physicomechanical Properties of NR/NBR Blends}

\subsubsection{Tensile Properties}

Fig. 4 presents the tensile strength of NR/NBR blend compounds. From the figure, the control has shown the highest tensile strength (13 MPa) while all other blend compounds showed lower values compared to that. The tensile strength of blends has varied between $1 \mathrm{MPa}$ and $6 \mathrm{MPa}$. As reported by Hamed [20], this may be due to the weak interfacial crosslinking between NR and NBR phases. However, the tensile strength has increased up to NR/NBR 60:40 blend and then has decreased and can be attributed to the changing of the continuous phase of the blend. The variation of the tensile strain break is shown in Fig. 5. The control has shown around 180 percent tensile strain at the break while that of the blends varied from 50 percent to 174 percent. The incompatibility between NR and NBR phases and poor rubber-filler interaction could be assigned as this variation of tensile strain at break. Overall, a significant difference between the blending methods could not be observed in these blend compounds.

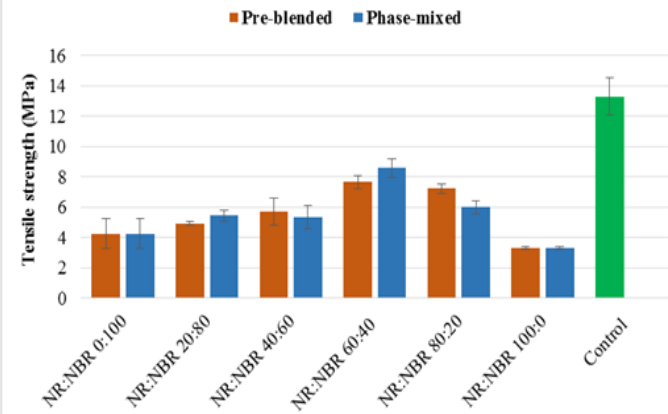

Fig. 4 Variation of the tensile strength of NR/NBR blend compounds

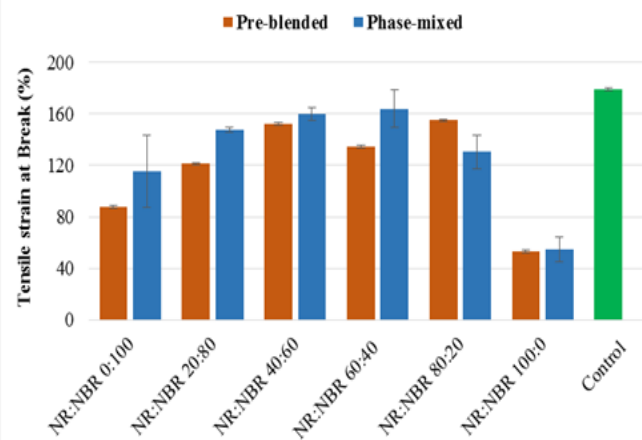

Fig. 5 Variation of the tensile strain at break of NR/NBR blend compounds 


\subsubsection{Tear Strength}

Fig. 6 shows the variation of the tear strength of NR/NBR blends. The control has shown a tear strength of $38 \mathrm{Nmm}^{-1}$ while the other blend compounds have shown tear strength ranging from $6 \mathrm{Nmm}^{-1}$ to $16 \mathrm{Nmm}^{-1}$. This comparatively lower tear strength may be attributed to weak interfacial crosslinking between NR/NBR phases [20]. The tear strength has been increased up to NR/NBR 40:60 and NR/NBR 60:40 blends and then decreased due to NR and NBR phase changes.

Also, the poor rubber-filler interactions between NR and RHANS could drive that compound (NR: NBR 100:0) to inferior properties. Tokita [21] has reported that the domain size of the blends does not affect the tear strength. However, a significant difference between blending methods cannot be observed, and therefore, it can be reported that there is no effect of the blending method on the tearing strength of NR/NBR blend compounds.

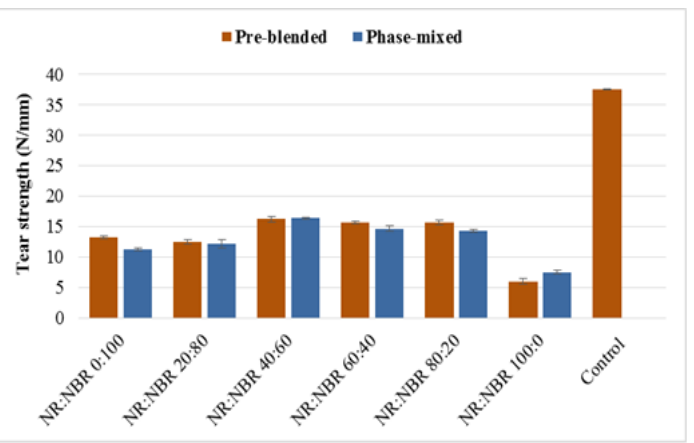

Fig. 6 Variation of the tear strength of NR/NBR blend compounds

\subsubsection{Hardness}

Fig. 7 shows the variation of the hardness of NR/NBR blends. The highest hardness has been shown by the control (73 International Rubber Hardness Degrees - IRHD) while the blends show comparatively lesser hardness values ranging from 47 IRHD to 70 IRHD. Also, the hardness of blends has decreased with the increment of NR content in blends up to $40 \%$ and $60 \%$ (NR: NBR 40:60 and NR: NBR 60:40). This behavior can be related to the changing of the continuous phase of the blends. However, the higher hardness values are accounted for the blends with a higher NBR content since the high stiffness NBR than NR.

As reported by Edirisinghe [7], the polarity due to the presence of cyanide groups $(-\mathrm{CN})$ and the formation of network among fillers and other polar compounds in the mixture may be some reasons for higher hardness in such blends. However, a significant difference between the methods of blending cannot be found. Therefore, there is no evidence to report that these blending methods affect the hardness of blends.

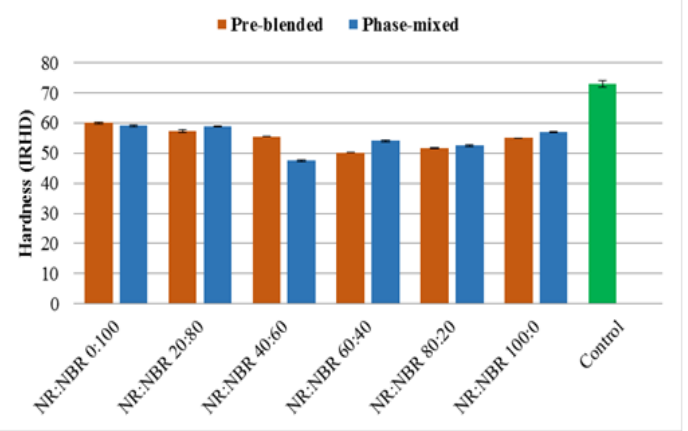

Fig. 7 Variation of the hardness of NR/NBR blend compounds

\subsubsection{Compression Set Percentage}

The variation of compression set (\%) of NR/NBR blends is shown in Fig. 8. It reveals that the compression set of the control is about $4 \%$. The compression set (\%) of blends have varied between $1 \%$ and $6 \%$. Since this property represents the deformation of viscoelastic rubber materials against a prolonged constant compression stain at a given temperature, the lower compression set values indicate better elasticity. Therefore, such materials could be used in fluid sealing applications [22]. It can be observed that the compression set (\%) of blends has increased up to NR/NBR 60:40 and has decreased thereafter. This could be due to the changing of the continuous phase. Comparatively lower compression set (\%) has been observed when the NBR amount is higher. This may be attributed to the high stiffness of NBR that occurs due to the presence of polar cyanide $(-\mathrm{CN})$ groups and silica of compatibility with NBR. Further, https://doi.org/10.30799/jnst.319.21070101 the results indicate the excellent compression set (\%) properties can be achieved with the reinforcement of RHANS since all the values are comparable with the control. As per the results, the method of blend preparation has not significantly affected to vary this property. Therefore, there is no sufficient evidence to report that the blending method affects the compression set (\%) of NR/NBR blends.

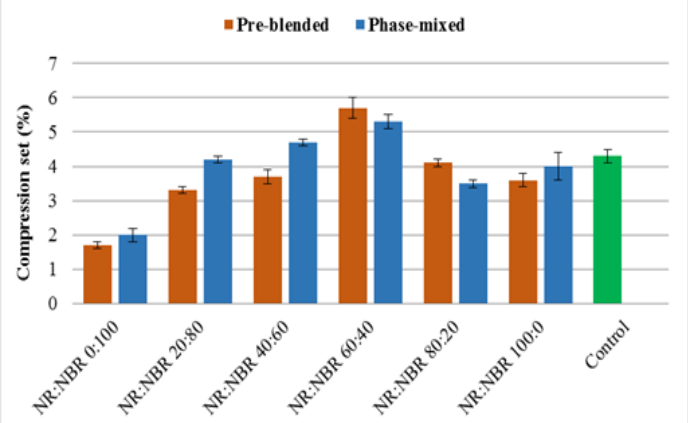

Fig. 8 Variation of the compression set of NR/NBR blends

\subsubsection{Equilibrium Swelling Percentage}

The equilibrium swelling (\%) of NR/NBR blends in toluene has shown in Fig. 9. The control sample has shown about $82 \%$ swelling at equilibrium while the blend compounds containing RHANS show some higher values than that. This property of other NR/NBR blends has ranged from $78 \%$ to $152 \%$.

The lower swelling percentages in the blends with a high amount of NBR occur due to the tolerance to non-polar solvents by NBR since the NBR is polarity because of the - CN groups present in the main chain [23]. Also, this high swelling percentage could be attributed to the low crosslinking density of RHANS filled blends and poor rubber-filler interaction of blends. However, toluene has a high affinity towards NR due to its non-polar nature; hence the swelling percentage at equilibrium has increased with the increment of the NR ratio of the blends. But a significant difference between the methods of blending cannot be observed, thus it can be reported that equilibrium swelling (\%) has not been affected by the blending method.

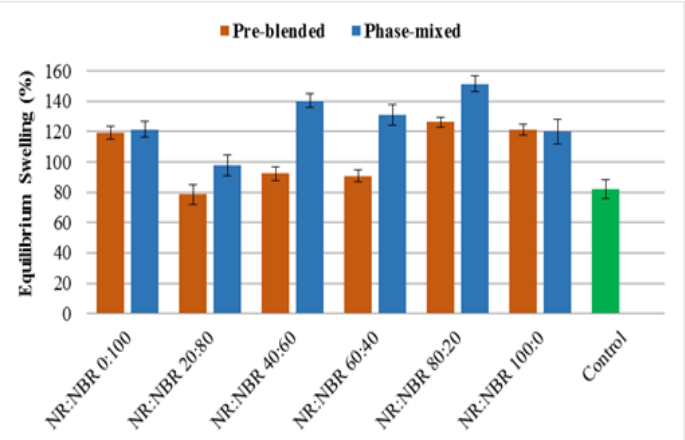

Fig. 9 Variation of the equilibrium swelling percentage of NR/NBR blends

\section{Conclusion}

According to the overall results of this study, the nano silica extracted from rice husk ash has a possibility to use in NR/NBR blends while having acceptable levels of physical properties. Since both pre-blending and phase-mixing methods have shown almost similar values for each property investigated in this study, it can be concluded that there is no effect of the blending method on the properties of these NR/NBR blends.

\section{Acknowledgement}

The authors would like to express our sincere gratitude to the Uva Wellassa University of Sri Lanka, Badulla, Sri Lanka for providing laboratory facilities (Rubber Technology Laboratory) and funds through a short-term research grant of UWU/RG/ST/2019/009 for this research study. As well as the Faculty of Applied Sciences of the Uva Wellassa University of Sri Lanka is appreciated for providing us XRD and FTIR testing facilities. Also, authors especially thank the Department of Rubber Technology and Development, Rubber Research Institute of Sri Lanka, Rathmalana, Sri Lanka for providing laboratory testing facilities for this study. 


\section{References}

[1] A. Yuniari, H.E. Mayasari, I. Setyorini, Curing characteristics, swelling, and mechanical properties of natural rubber/nitrile butadiene rubber blends with and without compatibilizer, Majalah Kulit Karet dan Plastik 33(2) (2017) 6572.

[2] H.S. Ahmad, H. Ismail, A.R. Azura, Comparison properties of natural rubber/virgin acrylonitrile-butadiene rubber and natural rubber/recycled acrylonitrile-butadiene rubber blends, Iran Polym. J. (English Ed.) 24(3) (2015) 185-195.

[3] B. Rodgers, A. Halasa, Compounding and processing of rubber/rubber blends, in: Encyclopedia of Polymer Blends [Internet], Weinheim, Germany, 2016, pp.163-206.

[4] J.O.B.K. Aerankavil, Studies on elastomer blends with special reference to NBR/Butyl, NR/Butyl, and NBR/EPDM blends, (1996). Available from: http://dyuthi.cusat.ac.in/purl/3475 (Accessed on: $14^{\text {th }}$ December 2020).

[5] G.M. Bristow, NR Technology, in: M. Mortan (Ed.), Rubber Technology, 3rd Ed., Springer, US, 1999.

[6] M.V. Lewan, Blends of natural rubber, $1^{\text {st }}$ Ed., A.J. Tinker, K.P. Jones (Eds.), 1998, pp.68-78.

[7] D.G. Edirisinghe, The influence of mixing on the morphology and properties of blends of natural and nitrile rubber, Loughborough University, United Kingdom, 1999.

[8] S. Angnanon, P. Prasassarakich, N. Hinchiranan, Styrene/acrylonitrile graft natural rubber as compatibilizer in rubber blends, Polym.-Plast. Technol. Eng. 50(11) (2011) 1170-1178.

[9] Y. Chen, Z. Peng, L.X. Kong, M.F. Huang, P.W. Li, Natural rubber nanocomposite reinforced with nano silica, Polym. Eng. Sci. 48(9) (2008) 1674-16777.

[10] B.P. Kapgate, C. Das, D. Basu, A. Das, G. Heinrich, Rubber composites based on silane-treated stöber silica and nitrile rubber: Interaction of treated silica with rubber matrix, J. Elastomers Plast. 47(3) (2015) 248-261.

[11] K. Subramaniam, Fundamental of rubber technology, $1^{\text {st }}$ Ed., Kumaran Press (Pvt) Ltd., Colombo, 2002.
[12] B.S. Todkar, O.A. Deorukhkar, S.M. Deshmukh, Extraction of silica from rice husk, Int. J. Eng. Res. Dev. 12(3) (2016) 69-74.

[13] D.N. Subbukrishna, K.C. Suresh, P.J. Paul, S. Dasappa, Precipitated silica from rice husk ash by IPSIT process, $15^{\text {th }}$ Eur. Biomass Conf. Exhib, 7-11 May 2007, Berlin, Germany, 2007, pp.7-11.

[14] L.A.E.M. Reuvekamp, J.W. ten Brinke, P.J. van Swaaij, J.W.M. Noordermeer, The effects of mixing conditions reaction of TESPT silane coupling agent during, Kautschuk Gummi Kunststoffe 75(2) (2002) 187-198.

[15] M.T. Ramesan, R. Alex, N.V. Khanh, Studies on the cure and mechanical properties of blends of natural rubber with dichlorocarbene modified styrenebutadiene rubber and chloroprene rubber, React. Funct. Polym. 62(1) (2005) 41-50.

[16] W.A.P.J. Premaratne, W.M.G.I. Priyadarshana, S.H.P. Gunawardena, A.A.P. De Alwis, Synthesis of nanosilica from paddy husk ash and their surface functionalization, J. Sci. Univ. Kelaniya Sri Lanka 8 (2013) 33-48.

[17] N. Thuadaij, A. Nuntiya, Preparation of nanosilica powder from rice husk ash by precipitation method, Chiang Mai J. Sci. 35(1) (2008) 206-211.

[18] S. Chuayjuljit, S. Eiumnoh, Using silica from rice husk as a reinforcing filler in natural rubber, J. Sci. Res. Chula. Univ. 26(2) (2001) 127-138.

[19] H. Essawy, D. El-Nashar, The use of montmorillonite as a reinforcing and compatibilizing filler for NBR/SBR rubber blend, Polym. Test. 23(7) (2004) 803-807.

[20] G.R. Hamed, How to design rubber components, in: A.N. Gent (Ed.), Materials and Compounds, Engineering with Rubber, Carl Hanser Verlag, Munich, 2012, pp.11-34.

[21] N. Tokita, Analysis of morphology formation in elastomer blends, Rubber Chem. Technol. 50(2) (1977) 292-300.

[22] A.M. Omran, A.M. Youssef, M.M. Ahmed, Mechanical and oil resistance characteristics of rubber blends based on nitrile butadiene rubber, Kautschuk Gummi Kunststoffe 63(5) (2010) 197-202.

[23] H. Ismail, H.S. Ahmad, A.A. Rashid, Fatigue, resilience, hardness, and swelling behaviour of natural rubber / recycled acrylonitrile-butadiene rubber (NR / NBRr) blends, 23(8) (2015) 583-588. 